EXEMPLARIa Classica

Journal of Classical Philology

17, 2013, pp. 27-44

ISSN 1699-3225

\title{
LAS CITAS DE EURÍPIDES EN EL GORGIAS DE PLATÓN*
}

\author{
$\mathrm{M}^{\mathrm{a}}$ Llanos Martínez Bermejo \\ Universidad de Salamanca \\ m_planitiarum@usal.es
}

SUMMARY

This work aims to analyse Euripides quotations from the Gorgias, considering their form, function and the way in which they are inserted in the dialogue. Not all quotations imply the same familiarity with the drama from which they were extracted and, for the most part, were adapted by Plato according to his interests.

KEYWORDS

Quotations, Euripides, Gorgias.
RESUMEN

Este trabajo pretende analizar las citas de Euripídes en el Gorgias atendiendo a su forma, función y su modo de inserción en el diálogo. No todas las citas implican la misma familiaridad con el drama del que fueron extraídas y la mayoría fueron adaptadas por Platón de acuerdo a sus intereses.

Palabras Clave

Citas, Eurípides, Gorgias.

Fecha de recepción: 04/04/2013

Fecha de aceptación y versión final: 19/07/2013

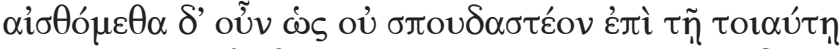

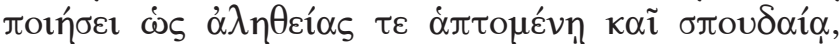

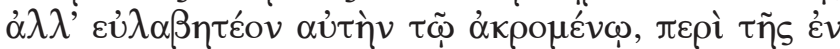

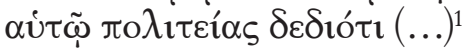

Estas palabras, que constituyen un testimonio del rechazo de Platón hacia la poesía mimética, suponen también una contradicción con el carácter imitativo de sus propias obras. No son pocos los estudiosos que se han ocupado

* Este trabajo ha sido realizado en el marco del Proyecto de Investigación FFI-2010-21125, financiado por el Ministerio de Ciencia e Innovación.

${ }^{1} \mathrm{Pl}$. Rep. 608a-b: "Así pues, entendemos que no se debe tomar con seriedad este tipo de poesía, como algo sujeto a la verdad y serio, sino que aquel que la escucha debe estar en guardia, temiendo por su gobierno interior (...)". 
de la relación del drama con los diálogos platónicos ${ }^{2}$, que no se limita a la estructura dialógica, sino que se plasma también en el pensamiento de Platón. De los tres grandes trágicos, el que más influyó en él es Eurípides: el filósofo habría podido ver algunas de sus tragedias representadas por primera vez ${ }^{3}$, así como representaciones posteriores. Después de la muerte del dramaturgo, su popularidad fue en aumento, y sus obras comenzarían a ser puestas en escena con bastante frecuencia a partir de 386, cuando habrían vuelto a ser representados dramas clásicos tanto en Atenas como en otras partes del mundo helénico ante la falta de originalidad de los nuevos ${ }^{4}$. Pese a su defensa de la oralidad frente a la escritura ${ }^{5}$, también a través de la lectura Platón habría tenido acceso a las tragedias de Eurípides: su difusión en forma de libros sería contemporánea al poeta, y quizás anterior a la representación teatral, si atendemos al testimonio de Aristófanes en Ranas ${ }^{6}$. Por otra parte, en esta época ya habrían comenzado a circular también las primeras antologías de versos, como sabemos por testimonios como el del propio Platón ${ }^{7}$, y en las que la presencia de Eurípides sería ya notable, según puede deducirse de la tradición indirecta.

Tal y como pone de manifiesto Sansone ${ }^{8}$, Platón cita a Eurípides tantas veces como a Esquilo y Sófocles juntos, sin contar otras ocasiones en las

${ }^{2}$ Cf., entre otros, H. Kuhn, "The True Tragedy: On the Relationship between Greek Tragedy and Plato" I, HSCPh 52, 1941, 1-40; II, HSCPh 53, 1942, 37-88; D. Clay, "The Tragic and Comic Poet of the Symposium", Arion 2, 1975, 238-61; R. Patterson, "The Platonic Art of Comedy and Tragedy", Philosophy and Literature 6, 1982, 76-93; J. Arieti, Interpreting Plato: The Dialogues as Drama, Savague, MD 1991; A. W. Nightingale, "Plato's Gorgias and Euripides' Antiope: A Study in Generic Transformation”, ClAnt 11, 1992, 121-41; D. Sansone, "Plato and Euripides", ICS 21, 1996, 35-67; M. Statkiewicz, "Platonic Theather: Rigor and Play in the Republic”, MLN115, 2000, 1019-51; R. Blondell, The Play of Characters in Plato's Dialogues, Cambridge 2002.

${ }^{3}$ En 415 , cuando Platón tenía doce años, se habría representado la trilogía compuesta por Troyanas, Alejandro y Palamedes (cf. Ael. VH 2.8); otras primeras representaciones a las que habría podido asistir son Helena y Andrómeda, representadas en 412 (cf. Schol. Ar. Th. 1012, 1040), Orestes en 408 (cf. Schol. Or. 371), Fenicias, cuya representación habría sido posterior a la de Andrómeda y anterior a la de Orestes (cf. Schol. Ar. Ra. 53), así como Ifigenia en Áulide, Bacantes y Alcmeón en Corinto, representadas en 406, tras la muerte de Eurípides (cf. Schol. Ar. Ra. 67).

${ }^{4}$ Cf. especialmente A. Pickard-Cambridge, The Dramatic Festivals of Athens, Oxford 1953, 100 ss. y A. Pertusi, "Selezione teatrale e scelta erudita nella tradizione del testo di Euripide", I, Dioniso 19, 1956, 112 ss.

${ }^{5}$ Cf. Pl. Phdr. 274b-9b.

${ }^{6}$ Ar. Ra. 1109-14. Sobre el texto de Eurípides en los siglos V-IV a. C., cf. A. Tuilier, Recherches Critiques sur la tradition du texte d'Euripide, Paris 1968, 23-39 y P. Carrara, Il testo di Euripide nell'Antichità, Firenze 2009, 13-8.

${ }^{7}$ En Leyes 810e-1a se discute si los jóvenes deben aprender obras enteras de memoria (ő $\lambda$ ous

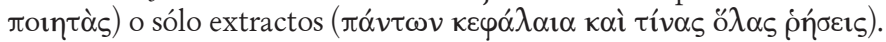

${ }^{8}$ Cf. Sansone, "Plato and Euripides", 41. 
que alude a él o a sus tragedias de una manera más implícita ${ }^{9}$. Brandwood ${ }^{10}$ contabiliza diecisiete citas del dramaturgo ateniense en el corpus platónico, diez de las cuales pertenecen a tragedias no conservadas en la tradición medieval. Este dato no resulta demasiado sorprendente si tenemos en cuenta que en la época de Platón el repertorio euripideo aún constaría de unos cincuenta dramas ${ }^{11}$; pero hay que tener en cuenta que, para la reconstrucción de algunos fragmentos de la Antiope, las citas del Gorgias tienen una importancia capital, al ser la fuente principal y casi la única en algunos casos.

De hecho, si hay un diálogo platónico en el que la influencia de Eurípides es notoria, es el Gorgias. Prueba de ello es la recreación que hacen Calicles y Sócrates de la disputa entre Anfión y Zeto en la Antíope sobre la vida activa y la vida contemplativa ${ }^{12}$, de la que Platón cita cuatro fragmentos ( $\left.\operatorname{Tr} G F 5.1^{13} 184,185,186,188\right)$, además de uno del Poliido (TrGF 5.2 638). Nightingale sostiene que Platón se apropió intencionadamente de algunos aspectos fundamentales de la temática y la estructura de la Antiope; pero además, esa apropiación y transformación de elementos no sólo de la tragedia, sino también de la comedia, da pie a la autora para examinar de qué manera el diálogo platónico se constituye a sí mismo como género ${ }^{14}$. Creemos, sin embargo, que es necesario realizar un estudio intertextual más detallado, que atienda a las citas en cuanto a su forma, su función y el modo en que están insertadas en el texto de acogida, así como una confrontación con las demás fuentes transmisoras de los fragmentos, que nos permita valorar mejor el texto platónico ${ }^{15}$. Por otra parte, veremos que el uso que hace Platón de los

${ }^{9}$ En la parte final de su trabajo (61-67) Sansone ofrece una lista de cuarenta y dos citas y alusiones a Eurípides en la obra de Platón, mezclando ambas categorías.

${ }^{10}$ L. Brandwood, A Word Index to Plato, Leeds 1976, 995-6.

${ }^{11}$ Cf. Pertusi, "Selezione teatrale", 121.

${ }^{12}$ Existe una abundante bibliografía sobre estos dos géneros de vida en la Antigüedad. Bruno Snell le dedica un capítulo a la Antiope en Scenes from Greek Drama, Berkeley-Los Angeles 1964, 70-98. Destacamos también los trabajos de A. Grilli, Il problema della vita contemplativa nel mondo greco-romano, Milano 1953; R. Joly, Le theme philosophique des genres de vie dans l'antiquité classique, Bruxelles 1956, 186-92; G. R. Slings, "The Quiet Life in Euripides' Antiope”, en W. Hoffmann-A. Harder, Fragmenta dramatica, Göttingen 1991, 137-51.

${ }^{13}$ Nos referiremos a cada fragmento con el número a él asignado en R. Kannicht, Tragicorum Graecorum Fragmenta vol. 5.1-2: Euripides, Göttingen 2004.

${ }^{14}$ Cf. Nigthingale, "Plato's Gorgias",141: “This coupling of the low and the high, the clownish and the serious, produces a vigorous hybrid: a test that constitutes itself by appropriating and defamiliarizing both tragedy and comedy".

${ }^{15}$ No existe, hasta donde sabemos, ningún trabajo sobre las citas de Eurípides en Platón; sí contamos, no obstante, con numerosos precedentes en este tipo de estudios, de mayor o menor envergadura. Mencionamos aquí aquellos que, por su metodología, han prestado una mayor utilidad a nuestro trabajo; en primer lugar, los dedicados a Platón o a Eurípides: J. Labarbe, L'Homère de Platon, Paris-Liège 1949; D. Tarrant, "Plato's Use of Quotations and Other Illustrative Material”, CQ 44, 1951, 59-67; L. Di Gregorio "Lettura diretta e utilizzazione di fonti intermedie nelle citazioni plutarchee dei tre grandi tragici, I-II”, Aevum 53, 1979, 
fragmentos de la Antíope es distinto al del Poliido, además de implicar un nivel de familiaridad diferente con una y otra tragedia.

Analizaremos las citas en el orden en el que aparecen en el discurso; cada una irá encabezada por el número que le corresponde dentro del corpus de Tragicorum Graecorum Fragmenta, así como por la referencia al pasaje del Gorgias en el que se encuentra. A continuación, figurarán los textos con su correspondiente traducción, seguidos del análisis. Para el Gorgias, hemos tomado como base la edición de Dodds ${ }^{16}$; en cuanto a los fragmentos de Eurípides, el texto que reproduciremos será el de Kannicht ${ }^{17}$, excepto para el fragmento 185, donde hemos preferido la edición de Kambitsis ${ }^{18}$ por los motivos que explicaremos en su momento. Hemos tenido en cuenta, además, otras ediciones ${ }^{19}$.

Vamos a ocuparnos en primer lugar de las citas de la Antíope, de las que será necesario hacer una valoración tanto en su conjunto como individualmente. La incertidumbre sobre la fecha de la tragedia no deja claro si Platón pudo verla representada por primera vez, o si su conocimiento de la misma se debería a la asistencia a posteriores puestas en escena, o a la lectura ${ }^{20}$.

Todas las citas forman parte de la intervención de Zeto en el ya mencionado

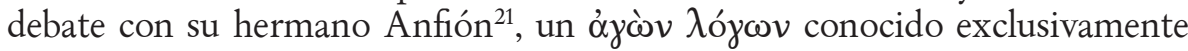
por la tradición indirecta y que constituye seguramente el pasaje más célebre

11-50 y Aevum 54, 1980, 46-79; P. Carrara, "Plutarco ed Euripide: alcune considerazioni sulle citazione Euripidee in Plutarco (de aud. poet.)”, ISC 13.2, 1988, 447-55; E. Calderón, "La tradición indirecta en la crítica textual griega: el texto de Eurípides en Plutarco", en M. Sanz-M. Librán (eds.), Verae Lectiones. Estudios de crítica textual y edición de textos griegos, Cáceres-Huelva 2009, 33-56. Dedicados a otros autores: M. Sanz Morales, Citas de Homero en Aristóteles, Classical and Byzantine Monographs, vol. XXVII, Amsterdam 1994; F. Pordomingo, "Les citations poétiques du De Iside et Osiride: leur fonction dans le traité", en L. Van der Stock, Rhetorical Theory and Praxis in Plutarch, International Plutarch Society IV International Congress (Leuven, July 3-6, 1996), Louvain-Namur 2000, 355-73; S. Perlman, "Quotations from Poetry in Attic Orators of the Fourth Century B.C", AJPh 85, 1964, 155-72; J. M. Díaz Lavado, Las citas de Homero en Plutarco, Zaragoza 2010.

${ }^{16}$ E. R. Dodds, Plato, Gorgias, A Revised Text with Introduction and Comentary, Oxford 1959.

${ }^{17}$ Kannicht, $\operatorname{Tr} G F 5.1-2$ (n. 14).

${ }^{18} \mathrm{~J}$. Kambitsis, L'Antiope d'Euripide, Athènes 1972.

${ }^{19}$ Destacamos la de A. Nauck, Tragicorum Graecorum Fragmenta, Leipzig $1889^{2}$ (suppl. adiecit B. Snell, Hildesheim 1964); F. Jouan-H. van Looy, Euripide, tome VIII: Fragments, $1^{\text {ère }} 4^{\text {e }}$ partie, Paris 1998-2003; C. Collard, M. J. Cropp-J. Gibert, Euripides, Selected Fragmentary Plays, II, Oxford 2004.

${ }^{20}$ Un escolio al v. 53 de Ranas de Aristófanes deja entrever una fecha de representación entre 411 y 407; de ser así, Platón habría podido asistir siendo muy joven. Sin embargo, los estudios de métrica realizados por T. Zielinski, Tragodumenon libri tres, Cracow 1925, 219-21 y M. Cropp-G. Fick, Resolutions and Chronology in Euripides. The Fragmentary Tragedies (BICS Suppl. 43), London 1985, 74-76, revelan que el estilo de la Antiope corresponde al de los años 427-19.

${ }^{21}$ Un resumen detallado del pasaje puede encontrarse en Jouan \& Van Looy, Fragments $1^{\text {ere }}$ partie, 228-32; Kambitsis, Antiope, XXII-XXX; Nightingale, "Plato's Gorgias", 123-6 y J.

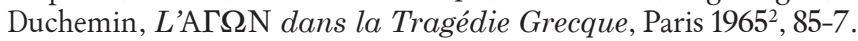


de la Antiope, a juzgar por la cantidad de autores que aluden a él ${ }^{22}$. La disputa surge por las diferencias en el modo de vida de ambos hermanos: Zeto es partidario de una vida dedicada al trabajo en el campo y al cultivo del cuerpo, mientras que Anfión prefiere dedicar su existencia a la música y al estudio en general, considerando que la sabiduría tiene mucho más valor que la fuerza física y la riqueza. Los ecos de este debate en el Gorgias son evidentes: para Calicles, la filosofía no es una ocupación digna de un hombre maduro, sino que sólo tiene utilidad en la juventud; al igual que Zeto, es un hombre de negocios, partidario de una vida activa que pueda conferirle poder, en su caso con dedicación a la oratoria y a la política. Por el contrario, Sócrates defiende que la mejor forma de vida tanto para el individuo como para la ciudad es la que lleva el filósofo, consistente en practicar la justicia y todas las demás virtudes. Pero mientras que Calicles asume el papel de Zeto ${ }^{23}$, y cita partes de su discurso en al menos cuatro ocasiones entre 484 e y 486 c, Sócrates no termina de verse como Anfión ${ }^{24}$, y no se sirve de sus palabras en ningún momento.

Las citas se caracterizan por alternar partes parafraseadas con partes literales, a excepción del fragmento 185, donde no hay ni un solo verso que pueda estar reproducido literalmente. Por otro lado, mientras que los fragmentos 184 y 188 están bastante atestiguados en la tradición gnomológica, especialmente el primero, las fuentes para 185 y 186 son muy escasas, lo que ha hecho que los editores no hayan podido lograr una reconstrucción igual de satisfactoria en todos los casos. Sobre la forma de citar de Platón, Jouan \& Van Looy señalan que probablemente el filósofo recurriría a su memoria y que la precisión "n'est pas son fort"25; Carrara, apropósito del pasaje del Gorgias que nos ocupa, habla de "qualche incertezza di memoria" de los personajes del diálogo, cuya discusión estaría basada en los recuerdos de la representación teatral ${ }^{26}$. Es cierto que existen en las citas algunas alteraciones sintácticas, que afectan al orden de palabras y a la coordinación de oraciones, y que podrían achacarse a lapsus memorísticos; pero es igualmente posible que se deban a un deseo por parte de Platón de adaptar el texto poético al estilo conversacional de su prosa: tal cosa sugieren los escolios del Gorgias ${ }^{27}$

${ }^{22}$ Se conservan al menos 18 fragmentos de la disputa: $\operatorname{Tr} G F 5.1184-9,191,193-202 ; 220$ y 219, atribuidos a Zeto por Kambitsis, también podrían formar parte de la misma.

${ }^{23}$ En 485e Calicles declara sentir por Sócrates algo parecido a lo que Zeto debió sentir por

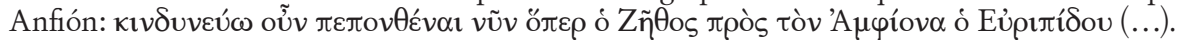

${ }^{24}$ En 506b Sócrates lamenta no poder devolverle a Calicles el pasaje de Anfión a cambio

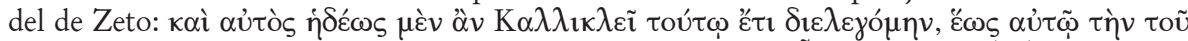

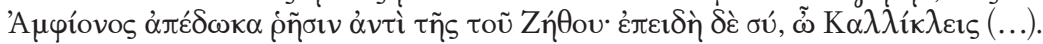

${ }^{25}$ Cf. Jouan-Van Looy, Fragments, 1 ère partie, XXXIV.

${ }^{26}$ Cf. Carrara, Il testo d'Euripide, 18.

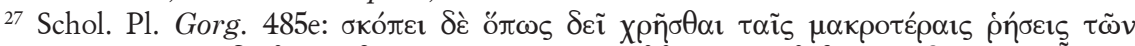

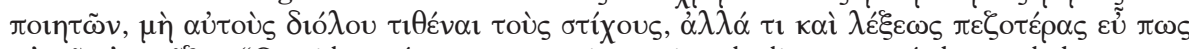
$\alpha$ $u ̛ \tau o i ̄ s ~ \alpha ́ v \alpha \mu i \tilde{\xi} \alpha$. "Considera cómo es necesario servirse de discursos más largos de los poetas, esto es, no reproducir totalmente los versos, sino mezclarlos convenientemente con un estilo 
y Olimpiodoro ${ }^{28}$, y también Tarrant observa algo similar en algunas citas de Homero, cuya inexactitud no se debería a un error de Platón, sino que sería intencionada ${ }^{29}$. Al margen de estas alteraciones, veremos que existen otro tipo de variaciones (cambios de palabras, supresiones de versos) que sin duda el filósofo llevó a cabo a propósito para adaptar las palabras de Zeto a las necesidades de Calicles, ya que, aunque ambos comparten en este caso una visión similar, su vida no transcurre en el mismo contexto.

El interés de Platón, por tanto, no es simplemente evocar el debate de Anfión y Zeto, sino adecuarlo al tiempo y las circunstancias de los protagonistas de su diálogo. El conjunto de las citas no tiene únicamente un valor ornamental, sino que juega un papel fundamental en el desarrollo argumentativo del discurso de Calicles, adquiriendo una función lógica, que podríamos considerar erudito-amplificativa ${ }^{30}$.

\section{Gorgias $484 \mathrm{e}: \operatorname{Tr} G F 5.1184$}

Dodds, Gorgias, 123-5:

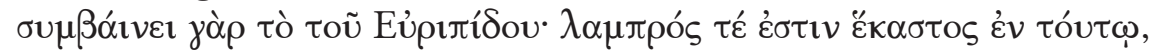

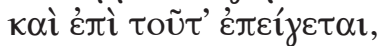

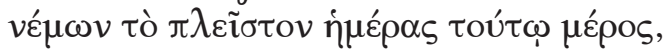

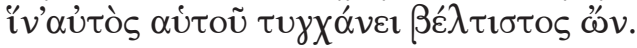

Pues sucede lo que dice Eurípides: cada uno es brillante en esto y en ello se esfuerza, "dedicando la mayor parte del día a aquello en lo que uno resulta ser mejor que sí mismo".

Kannicht, $\operatorname{TrGF} 5.1$ 184:

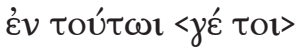

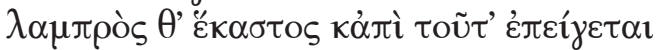

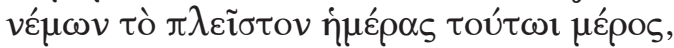

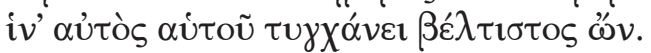

más prosaico".

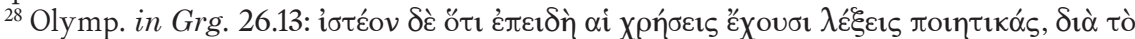

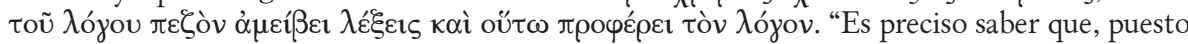
que las citas son en verso, las cambia por la prosa, y así procede el discurso".

${ }^{29}$ Cf. Tarrant, "Plato's Use of Quotations", 62: “The effect of this type of inexact quotation is to suggest casual reminiscence of a generally known original. While such an incorrectness may be due to Plato's own mistake, it seems far more probable that we should regard it as intentionally written and as meant to convey either conversational informality (...)".

${ }^{30}$ Remitimos a la tipología funcional de las citas de Díaz Lavado, Las citas de Homero, 154-157, que define las erudito-amplificativas como aquellas que "exponen la doctrina o pensamiento del autor estudiado, pero con un sesgo personal e interpretativo que le sirve al autor citante para exponer sus propias teorías y convicciones". 
Sabemos por el escoliasta del Gorgias y por Olimpiodoro ${ }^{31}$ que el presente fragmento pertenece a la Antiope y que forma parte de la rhesis de Zeto. Calicles lo cita en su idea de que la ambición personal por brillar en aquello en lo que cada uno es mejor puede llevar a dedicarle demasiado tiempo y a apartarse de las cosas importantes para el bien común, con el consiguiente menosprecio por lo desconocido. Concretamente, se está refiriendo a la dedicación de Sócrates a la filosofía, que le aleja de las costumbres habituales ( $\tau \tilde{\omega} v \hat{\eta} \theta \omega \nu)$, como puedan ser el conocimiento de las leyes de la ciudad ( $\tau \tilde{\omega} v$

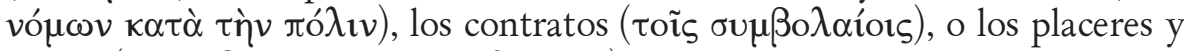

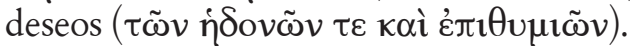

La cita está introducida por un nexo nominal ${ }^{32}$, el artículo neutro $\tau$ ò, que

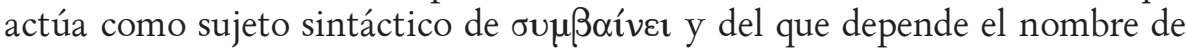
Eurípides en genitivo. Teniendo en cuenta la métrica, sólo el final del segundo

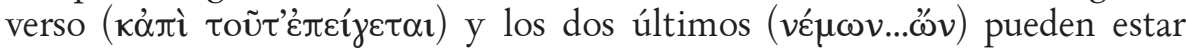
citados de forma literal; contamos con la dificultad de que no hay ninguna otra fuente que transmita el comienzo del fragmento, por lo que tenemos que atender a la reconstrucción de los editores modernos. De acuerdo a ésta, el tipo de alteraciones en la parte inicial de la cita parece deberse a una adaptación sintáctica y estilística. Por un lado, habría tenido lugar una

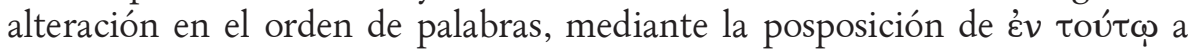

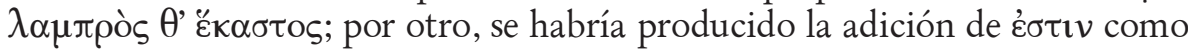

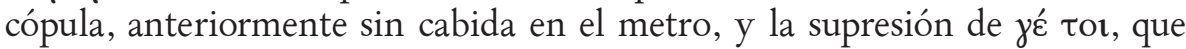
actuando como elemento enfático en su contexto original, pierde sentido en el texto de acogida.

Por lo que respecta al resto del fragmento, la versión de Platón es la

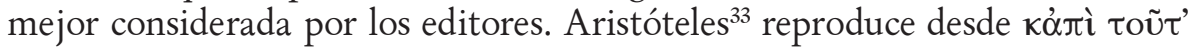

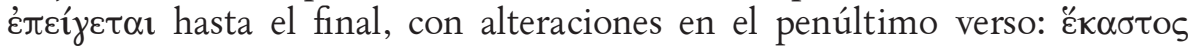

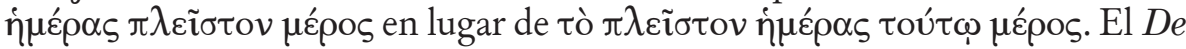
Garrulitate de Plutarco ${ }^{34}$ presenta la misma lectura que Platón, y también la obra Problemata ${ }^{35}$, considerada pseudo-aristotélica, con la única variante de

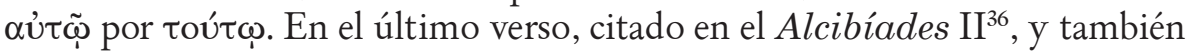

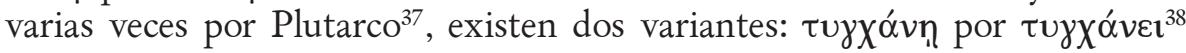

${ }^{31}$ Cf. Olymp. in Grg. 26.13.

32 Seguimos la tipología de marcas deícticas establecida por Díaz Lavado, Las citas de Homero, 93-105.

${ }^{33}$ Cf. Arist. Rh. $1371 \mathrm{~b}$.

${ }^{34}$ Cf. Plu. Garr. 514A.

${ }^{35} \mathrm{Cf}$. [Ar.] Pr. 917a.

${ }^{36} \mathrm{Cf} .[\mathrm{Pl}$.$] Alc. II 146 \mathrm{a}$.

${ }^{37}$ Quaest. conv. 630B, 622A; Aud. 43B.

${ }^{38}$ El códice T del Gorgias, el A de la Retórica de Aristóteles, el Pseudo-Aristóteles y

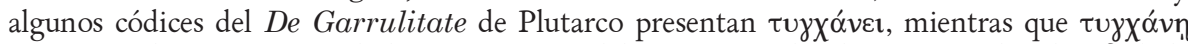
aparece en la mayor parte de los manuscritos del Gorgias y de Plutarco, en el códice $\beta$ de la Retórica y en el Alcibiades II. 


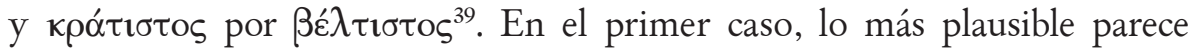

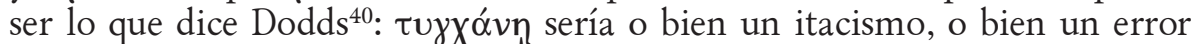
provocado por la presencia de îva, frecuentemente usado como conjunción final con subjuntivo. En el segundo caso, todos los manuscritos del Gorgias y la Retórica atestiguan $\beta \varepsilon ́ \lambda \tau \imath \sigma \tau o s$, considerada como la lectura correcta; крó como prueba su presencia ya en el Alcibíades II, de dudosa autoría platónica $\mathrm{y}$ datado en torno a finales del s. IV o principios del III a.C ${ }^{41}$.

\section{Gorgias $485 \mathrm{e}-486 \mathrm{a}$ : $\operatorname{Tr} G F 5.1185$}

Dodds, Gorgias, 125:

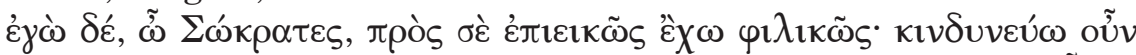

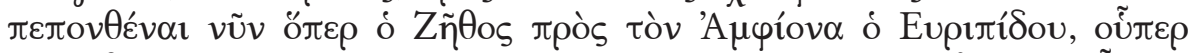

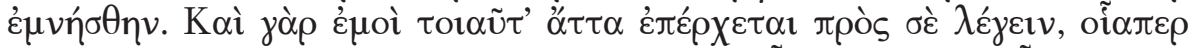

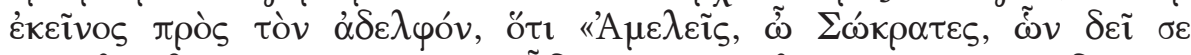

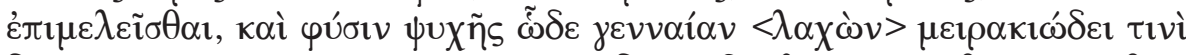

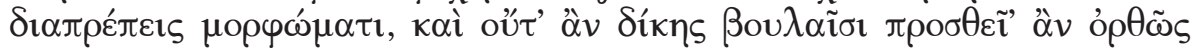

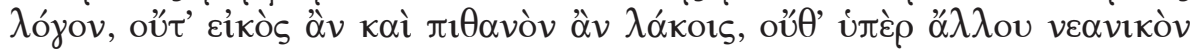

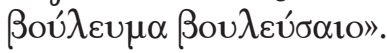

Yo, Sócrates, siento bastante amistad por ti; así pues, puede suceder que experimente ahora lo que Zeto por obra de Anfión, el personaje de Euripides al que he hecho mención. También a mí se me ocurre decirte cosas semejantes a las que precisamente le dijo aquel a su hermano, que "descuidas, Sócrates, aquello de lo que es necesario preocuparse, y poseyendo una naturaleza de alma tan noble, te distingues por una apariencia juvenil, y no podrías aportar ni una palabra correctamente en las deliberaciones de justicia, ni dirías nada verosimil ni convincente, ni tomarías una decisión audaz en favor de otro".

Kambitsis, Antiope, 3-4:

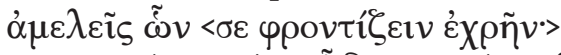

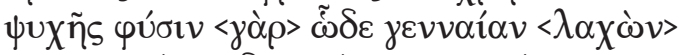

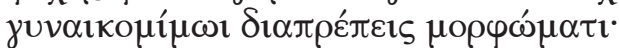

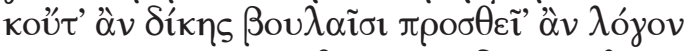

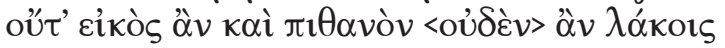

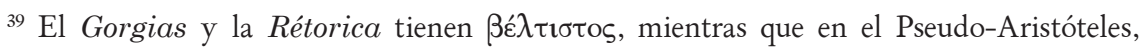

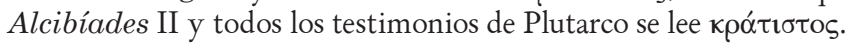

${ }^{40}$ Cf. Dodds, Gorgias, 274.

${ }^{41}$ Cf. J. Souilhé, Platon, Oeuvres Complètes, Tome XIII, $2^{\mathrm{e}}$ partie, Dialogues Suspects, Paris 1930, 9-18. 


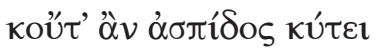

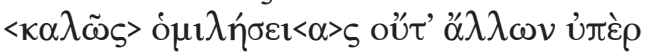

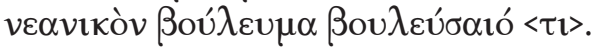

Descuidas aquello de lo que debes preocuparte, pues poseyendo una naturaleza del alma tan noble, te distingues por una apariencia afeminada y no podrías aportar ni una palabra correctamente en las deliberaciones de justicia, ni anunciar nada verosímil ni convincente (...) ni podrías luchar bravamente escudo en mano, ni tomar una decisión audaz en favor de otros.

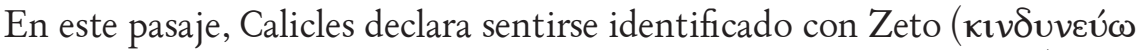

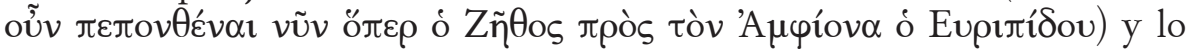
menciona por primera vez explícitamente, si bien dice haberse referido a él

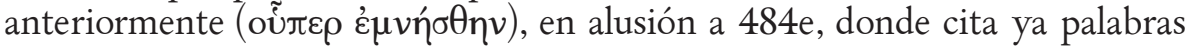
suyas, pero atribuyéndolas a Eurípides. Antes de introducir la cita, sirviéndose de la conjunción completiva ótı, dependiente de un verbum dicendi, $\lambda \varepsilon ́ \gamma \varepsilon ı v$, Calicles anuncia que dirá a Sócrates palabras semejantes a las que Zeto dedicó

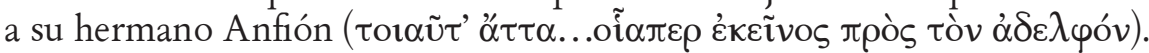

Tanto Zeto como Calicles se refieren a una serie de obligaciones propias de ciudadanos a las que Anfión y Sócrates deberían atender, en lugar de dedicarse a la filosofía y a la música, respectivamente. Ahora bien, no todo lo que dice Zeto le sirve a Calicles para su discurso, y a ello se deberían algunas de las divergencias que presenta el texto de Platón con respecto al de la Antíope, como veremos a continuación. El Gorgias es la única fuente que transmite este fragmento, a excepción de los pequeños apuntes que nos proporcionan Olimpiodoro y Filóstrato ${ }^{42}$; por otro lado, aunque la paráfrasis que hace Platón se parecería bastante al texto euripideo, la disolución métrica es total. Ambas dificultades hacen que los editores únicamente puedan ofrecer una reconstrucción aproximada del original, basándose en el testimonio del Gorgias y en sus propias conjeturas. No tiene sentido, por tanto, comentar todas las diferencias entre ambos textos, de modo que atenderemos a aquellos elementos del discurso que Platón habría modificado de manera intencionada. Existen, además, algunas variaciones sintácticas, así como adiciones y supresiones de palabras de menor importancia que no alteraron el sentido del texto, y que se deberían bien a imprecisiones de memoria, bien a una mera cuestión de adecuación al estilo del texto de acogida.

El testimonio de Filóstrato es clave para la reconstrucción del segundo

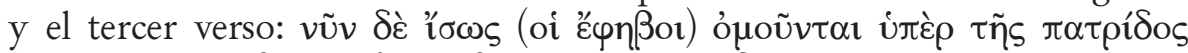

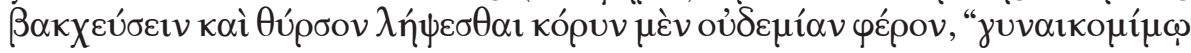

${ }^{42}$ Cf. Olymp. in Grg. 26.20-22; Philostr. VA 4.21. 


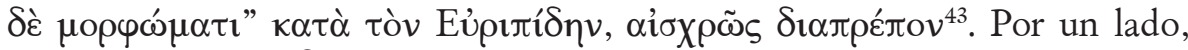
confirma la lectura $\delta \_\pi \tau \rho \dot{\pi} \varepsilon \varepsilon \varsigma$ y su valor intransitivo, que obliga a la inserción de un participio para regir $\varphi v ́ \sigma ı v(\lambda \alpha \chi \omega \dot{v})^{44}$; por otro, nos devuelve la lectura

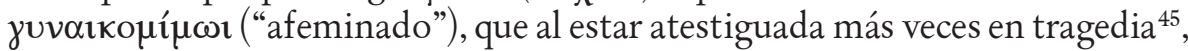

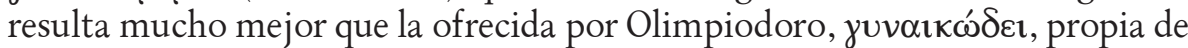
la prosa. El calificativo yuvaıкouífuı no es nada apropiado para Sócrates, dado el aspecto desaliñado que le atribuyen las fuentes; por el contrario, el

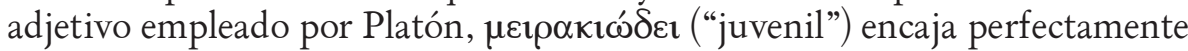
con él por su dedicación a la filosofía, a la que Calicles, como ya hemos apuntado, considera una actividad adecuada únicamente para jóvenes.

En los vv. 4-8, Zeto enumera una serie de ámbitos de la vida pública descuidados por Anfión, esto es, actividades relacionadas con la justicia

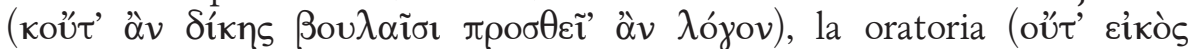

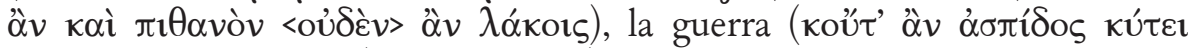

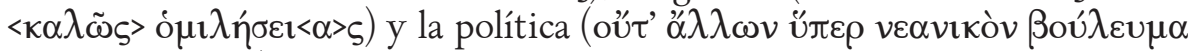

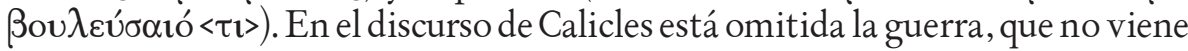
al caso en su debate con Sócrates. El testimonio de Olimpiodoro ${ }^{46}$ sugiere que

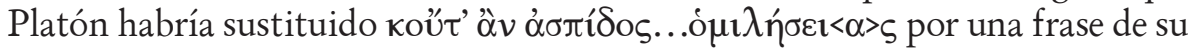

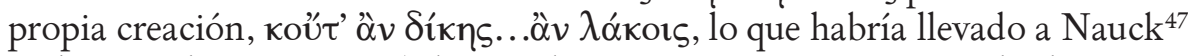
a eliminar los versos 4-5 de su edición, mientras que Kannicht hace una síntesis de ambos ${ }^{48}$. Seguimos a Kambitsis en su opinión de que los dos versos deben mantenerse, apelando tanto a su estilo, claramente poético (dativo en

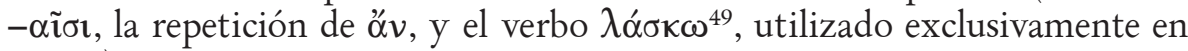
poesía), como al papel que juegan en el discurso de Zeto, imprescindible en su enumeración de los distintos ámbitos de la vida pública ${ }^{50}$.

43 "Ahora seguramente (los jóvenes) jurarán celebrar las fiestas en honor a Baco y blandir el tirso sin llevar ningún casco, distinguiéndose vergonzosamente por su 'apariencia femenina', como dice Eurípides".

${ }^{44}$ Cf. Dodds, Gorgias, 277 y Kambitsis, Antiope, 38-40.

${ }^{45}$ Cf. E. Bach. 980; A. Pr. 1005; S. Fr. 769.

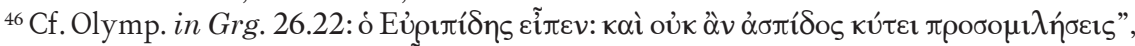

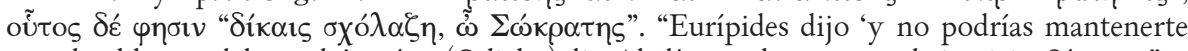
pegado al hueco del escudo', y éste (Calicles) dice 'dedícate a los asuntos de justicia, Sócrates”.

${ }^{47}$ Cf. Nauck, $T G F, 414-5$.

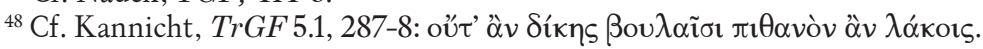

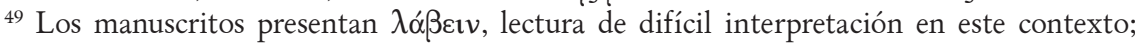
Bonitz corrigió en $\lambda$ ókєıv, que encaja perfectamente tanto en el Gorgias como en la Antíope. La confusión de ambos verbos constituiría un error bastante banal.

${ }^{50}$ Cf. Kambitsis, Antiope, 37-8. 


\section{Gorgias 486b : $\operatorname{Tr} G F 5.1186$}

Dodds, Gorgias, 126:

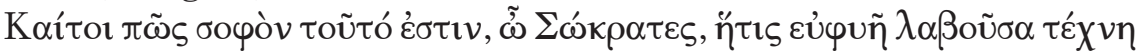

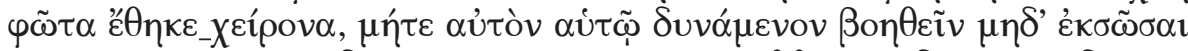

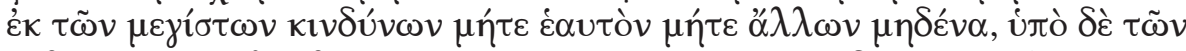

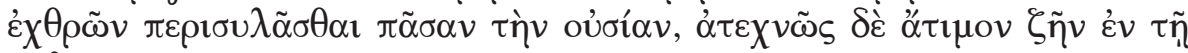
$\pi \hat{\lambda} \lambda \varepsilon$;

¿Pero qué sabiduría es esta, Sócrates, cuando un arte toma a un hombre de provecho y lo hace inferior, no siendo capaz de ayudarse a si mismo ni ponerse a salvo de los mayores peligros, ni a él ni a ninguno de los otros, y le deja ser despojado de su hacienda por los enemigos, y vivir, sin más, deshonrado en la ciudad?

Kannicht, $\operatorname{Tr} G F 5.1186$ :

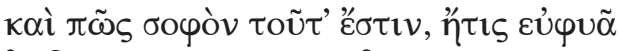

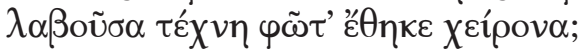

Continúa la argumentación de Calicles en contra de la filosofía: no

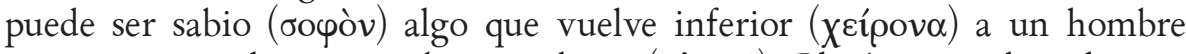
que por naturaleza tiene buenas dotes $(\varepsilon \dot{\varphi} \varphi v \tilde{\eta})$. Platón introduce la cita yuxtaponiéndola directamente al texto citante, y a diferencia de en la primera y la segunda, ya no menciona ni a Eurípides ni a los personajes de la Antiope; confiaría en la memoria de los receptores de su obra, que podrían haber visto representada la tragedia, incluso haberla leído.

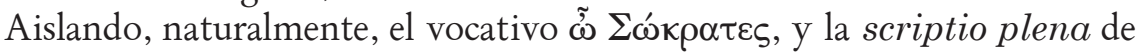

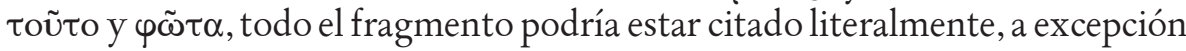

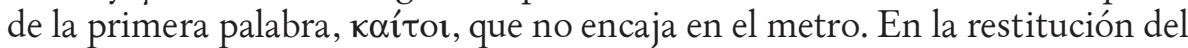

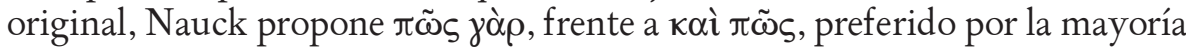
de los editores. La segunda opción expresa mejor, como advierte Kambitsis ${ }^{51}$, la indignación de Zeto ante la "ocurrencia" de Anfión de considerar la música como una $\tau \dot{x} \chi \nu \eta \eta$ seria, además de contar con paralelos en otras tragedias de Eurípides $^{52}$ y de acercarse más al kaítor de Platón, que expresa también la indignación de Calicles.

No existe ningún otro testimonio de estos versos, a excepción de una

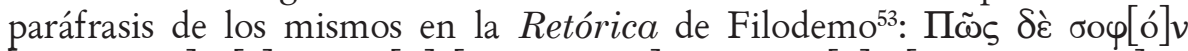

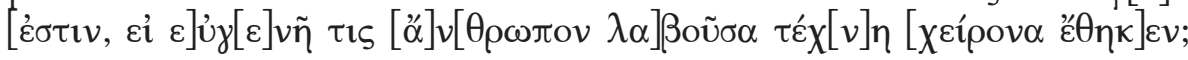

${ }^{51}$ Cf. Kambitsis, Antiope, 66.

${ }^{52}$ Alc. 142; Heraclid. 254; Ph. 900; Hec. 883.

${ }^{53}$ Cf. Phld. Rh. 2.176 (S. Sudhaus, Philodemus, Volumina Rhetorica, 2 vols., Leipzig 1892, 1896, Suppl. 1895). 
La lectura que contienen los códices B y F del Gorgias es 彳ৃंıs, preferible

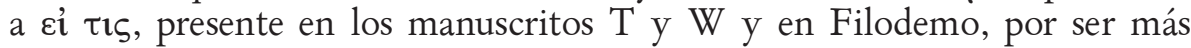
"idiomática" ${ }^{4}$. El carácter poético de $\varphi \tilde{\omega} \tau \alpha$ no deja ninguna duda de su preferencia ante ö $v \theta \rho \omega \pi$ ov, que se debería a una mera adaptación a la prosa de Filodemo; en cuanto a $\varepsilon \dot{\varphi} \varphi v \tilde{n}$, aplicable a alguien con buenas dotes naturales o "talento" natural, es preferible en este contexto a عủyevńs, referido más bien a la "nobleza" que otorga el haber nacido en una familia concreta.

Valckenaer ${ }^{55}$ creyó haber identificado un tercer verso, $\mu$ í $\tau^{\prime} \alpha u ̛ \tau o ̀ v ~ \alpha u ̛ \tau \tilde{~}$

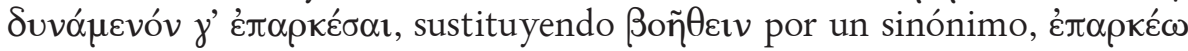
en infinitivo de aoristo, que aparece también en El Cíclope 301.

\section{Gorgias 486c : $\operatorname{Tr} G F 5.1188$}

Dodds, Gorgias, 126:

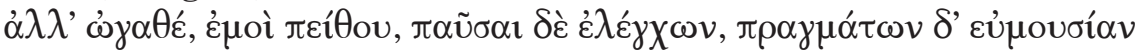

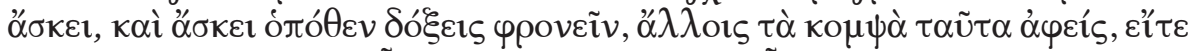

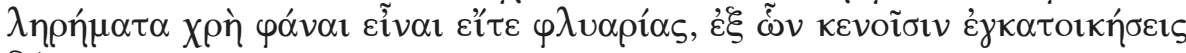
Sópors.

Pero amigo, hazme caso: cesa de argumentar, cultiva el talento para los negocios y cultiva el de aquello que te dé fama de hombre sensato; deja a otros esas ingeniosidades, que más bien hay que llamar sandeces o charlatanerías, por las que habitarás una casa vacía.

Kannicht, $\operatorname{Tr} G F$ 5.1188:

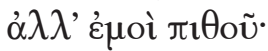

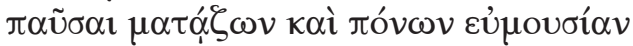

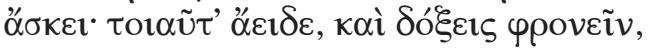

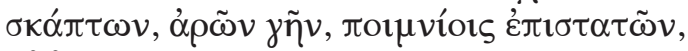

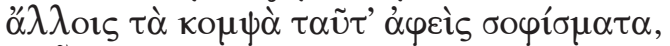

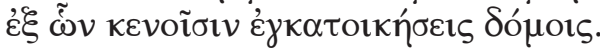

Pero hazme caso: para de actuar insensatamente y ejercita el talento del duro trabajo. Tales cosas debes cantar y parecerás sensato cavando, arando la tierra y cuidando los rebaños, dejando a otros esos artificios ingeniosos, por los que habitarás una casa vacía”.

La intervención de Calicles termina con una nueva cita de la Antíope, que Platón introduce en el texto, al igual que en el caso anterior, mediante yuxtaposición y sin hacer referencia a Eurípides o a otros datos del contexto

${ }^{54}$ Cf. Dodds, Gorgias, 278.

${ }^{55}$ L. C. Valckenaer, Diatribe in Euripidis perditorum dramatum reliquias, Leiden 1767. 
original. Calicles concluye aconsejando a Sócrates que se dedique de una vez a

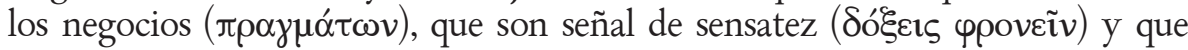
abandone la filosofía, a la que se refiere despectivamente como ко $\mu \psi \grave{\alpha}, \lambda \eta \rho \tilde{\eta} \mu \alpha \tau \alpha$

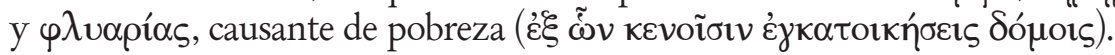

El único verso que el filósofo pudo haber citado de forma totalmente literal es el último, reproducido por Dión Crisóstomo en $D e$ fide ${ }^{56}$. El testimonio de Estobeo ${ }^{57}$, que cita los versos 3-5, y el de Olimpiodoro ${ }^{58}$, que con menor precisión se refiere a 2-3 y 5 , contribuyen también a la reconstrucción del fragmento, del cual Platón habría modificado y suprimido lo necesario para adaptarlo a las necesidades del discurso de Calicles, como trataremos de mostrar a continuación.

Al igual que en el comienzo de la cita anterior, un vocativo rompe el ritmo

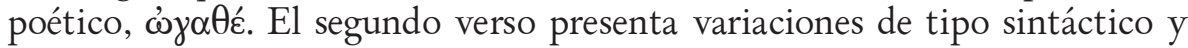
léxico: en el original, la oración de $\pi \alpha \tilde{u} \sigma \alpha \mathbf{\imath}$ estaría yuxtapuesta a la anterior, y unida a la siguiente por la conjunción coordinante koì; en el Gorgias, la partícula $\delta \dot{\varepsilon}$ es la que coordina las tres oraciones. Por lo que respecta al

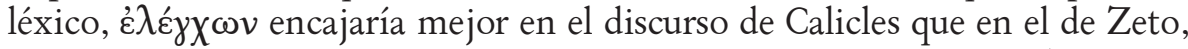
por lo que Platón lo habría empleado en lugar de otro participio ${ }^{59}$; lo más

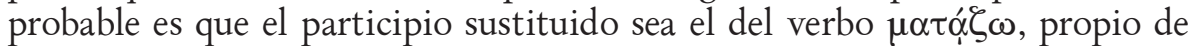
la tragedia y que no aparece en prosa hasta el s. I d.C. ${ }^{60}$ : el manuscrito P del

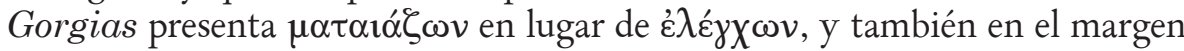
de TW aparece contemplado como variante ${ }^{61}$. La otra palabra que Platón

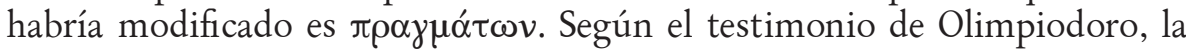
palabra sustituida sería $\pi \mathrm{o} \lambda \varepsilon \varepsilon^{\mu} \omega \nu^{62}$, pero es imposible desde el punto de vista

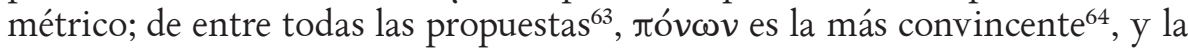

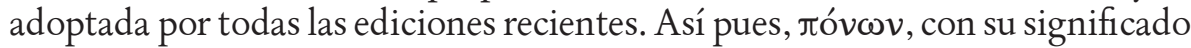
de "trabajo duro", encajaría perfectamente en el discurso de Zeto, haciendo referencia tanto a los trabajos del campo como al ejercicio físico, incluso a

${ }^{56}$ Cf. D. Chr. 73.10.

${ }^{57}$ Cf. Stob. 4.15.13. Sobre el texto de Eurípides en Estobeo, fuente principal para los fragmentos de las tragedias perdidas, remitimos especialmente a los trabajos de R. M. Piccione, "Sulle citazioni euripidee in Stobeo e sulla struttura dell'Anthologion", RFIC 122, 1994, 175-218 y F. Hernández, "Tipología de las faltas en las citas euripideas de los manuscritos de Estobeo", CFC 23, 1989, 131-55.

${ }^{58}$ Cf. Olymp. in Grg. 26.24-5.

${ }^{59}$ Cf. Dodds, Gorgias, 278.

${ }^{60} \mathrm{Cf}$. Kambitsis, Antiope, 44.

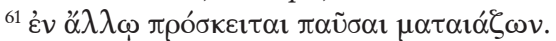

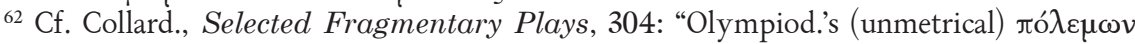
'warfare' was perhaps a deliberate change to suit Zethus' insistence on the merits of soldering".

${ }_{63}$ Todas las recoge Kambitsis, Antiope, 42-44.

${ }^{64}$ E. K. Bortwick, (“Two Textual Problems in Eur. Antiope, fr. 188”, CQ17, 1967, 41), sobre

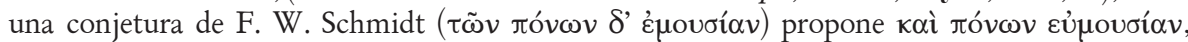
basándose en una carta de Teofilacto Simocates (R. Hercher, Epistolographi Graeci, Paris $1873, \mathrm{LXI})$ que presenta claros vínculos con el discurso de Zeto. 


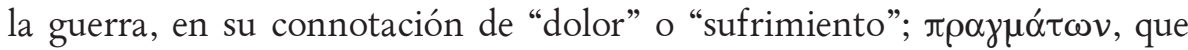
en este contexto puede entenderse como "negocios", públicos o privados ${ }^{65}$, incluso como "asuntos del Estado", se adapta mejor a las palabras de Calicles en su defensa de la oratoria como algo provechoso en la vida pública, frente a la inutilidad de la filosofía.

En el tercer verso, el verbo $\alpha \varepsilon i ́ \delta \omega$ no tiene sentido en el debate de Calicles y Sócrates, en el que la música no juega ningún papel, razón por la que Platón

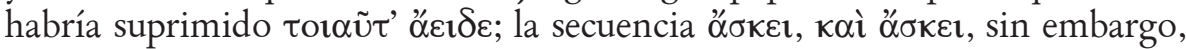
resulta bastante antiestética, y ha levantado las sospechas de algunos editores ${ }^{66}$.

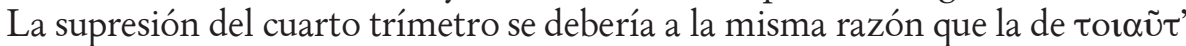
ócı $\delta \varepsilon ;$ al igual que la música, tampoco la vida agrícola entra en el debate del Gorgias.

La mayor parte del penúltimo verso está citado de forma literal, a excepción

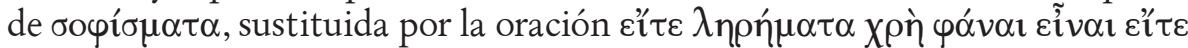

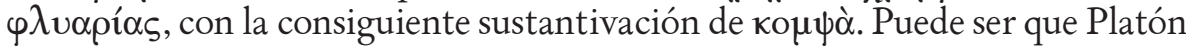
no recordase la palabra $\sigma o \varphi i ́ \sigma \mu \alpha \tau \alpha$, pero teniendo en cuenta la precisión con la que cita el resto del verso, la sustitución del último sustantivo por una oración entera parece una alteración demasiado notable como para deberse

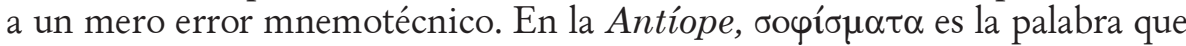
emplea Zeto para referirse a las actividades a las que se dedica Anfión y que

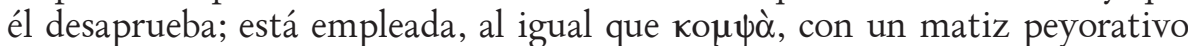
("artificios ingeniosos"). En el Gorgias, la actividad que Calicles no ve con buenos ojos es la filosofía; al ser ésta el principal objeto de sus críticas, en torno al que gira su discurso, quizá Platón quiso ir más allá y poner en su

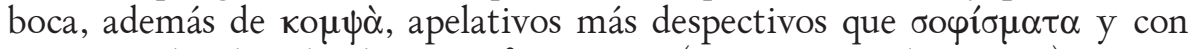
mayor poder de ridiculización: $\lambda \eta \rho \eta ́ \mu \alpha \tau \alpha$ ("tonterías", "desvaríos") aparece por primera vez en Platón como derivado de $\lambda \tilde{n} \rho o s$, empleado con cierta frecuencia por Aristófanes ${ }^{67} ; \varphi \lambda$ vopí $\alpha$ ("charlatanería") es también usada por el comediógrafo en Lisístrata 159, y ambas palabras aparecen juntas en otro fragmento a él atribuido ${ }^{68}$. Esta inserción de vocablos propios de la comedia en un fragmento trágico nos hace evocar las palabras de la República con las que hemos comenzado, en las que se niega el carácter serio de la tragedia (oủ

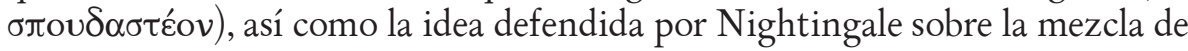
lo cómico y lo trágico en el Gorgias ${ }^{69}$.

${ }^{65}$ Esta distinción entre negocio público y privado la hace Calicles en $484 \mathrm{~d}$-e, a propósito

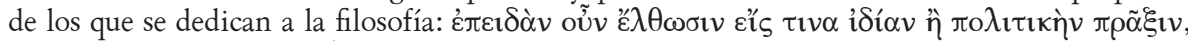

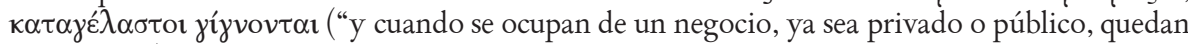
en ridículo").

${ }^{66}$ Cf. Dodds, Gorgias, 279.

${ }^{67}$ Cf. Lys. 680; Th. 880; Ra. 809; Nu. 359, etc.

${ }^{68}$ CGFP 62.18 (C. Austin, Comicorum Graecorum Fragmenta in Papyris Reperta,

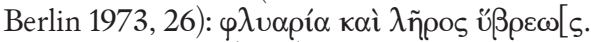

${ }^{69}$ Vid. supra (n. 15). 


\section{Gorgias 492e: $\operatorname{Tr} G F 5.2638$}

Dodds, Gorgias, 135:

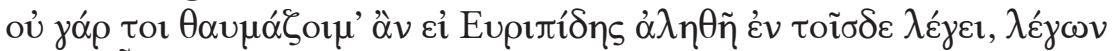

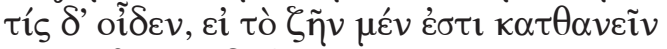

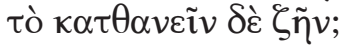

Pues no me sorprendería si Eurípides dice la verdad en estos versos, cuando dice: "¿quién sabe si vivir es morir, y morir vivir?

Kannitcht, $\operatorname{Tr} G F 5.2$ 638:

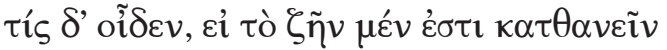

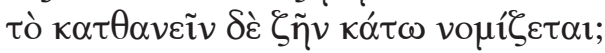

¿Quién sabe si vivir es morir, y morir se considera vivir en el más allá?

Calicles y Sócrates discuten sobre cómo hay que vivir para alcanzar la felicidad ${ }^{70}$. Para el primero, los deseos no deben reprimirse, sino saciarse, pues la virtud y la felicidad residen en el lujo, la intemperancia y la libertad, mientras que Sócrates es partidario de la autarquía: para él la felicidad es la ausencia de necesidad. Cuando Calicles aduce que, en ese caso, las piedras y los muertos serían felicísimos, Sócrates desmonta su argumento sirviéndose de las palabras de Eurípides, que según Sexto Empírico ${ }^{71}$, tendrían un antecedente

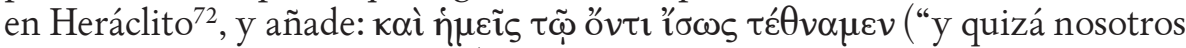
estamos en realidad muertos"). Este mismo pensamiento aparece también en el fr. 833, atribuido al Frixo, con gran paralelismo verbal ${ }^{73}$. La cita de Eurípides da pie a Platón para introducir el relato que sostiene la idea del $\sigma \tilde{\omega} \mu \alpha / \sigma \tilde{\eta} \mu \alpha^{74}$, con la que tratará de demostrar a Calicles que está equivocado en su concepción de la felicidad; no es, por tanto, un mero ornato, sino que influye en el desarrollo del discurso, desempeñando una función lógica.

Según el escolio a Ranas 1082, el fragmento pertenecería al Frixo, mientras que el escolio a Hipólito 192 lo atribuye al Poliido; ésta última atribución es

${ }^{70}$ Cf. Grg. 491e-5b.

${ }^{71}$ S.E. P. 3.230 .

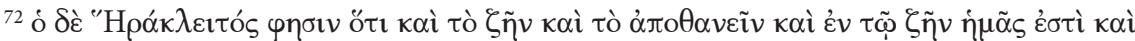

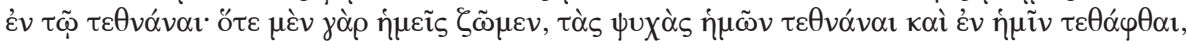

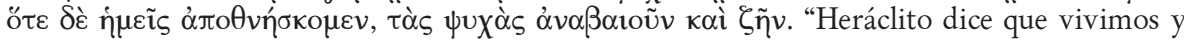
morimos tanto en la vida como en la muerte. Pues cuando vivimos, nuestras almas están muertas y enterradas en nosotros; en cambio, cuando morimos, las almas resucitan y viven".

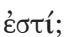

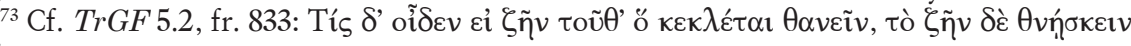

${ }^{74}$ Sobre las fuentes de las que Platón tomó el relato y su posible origen órfico, cf. A. Bernabé, "Una etimología platónica: “ $\sigma \tilde{\omega} \mu \alpha / \sigma \tilde{\eta} \mu \alpha ”$, Philologus 139, 1995, 204-37. 
la preferida por los editores. Lo que conservamos de Poliido se lo debemos exclusivamente a la tradición indirecta, tratándose mayoritariamente de fragmentos de carácter gnómico. Atendiendo a la reconstrucción del argumento por Jouan y Van Looy ${ }^{75}$, las palabras citadas por Platón serían las pronunciadas por Poliido cuando Minos, tras una disputa ${ }^{76}$ entre ambos, le ordena que se encierre en la tumba con el cadáver de su hijo Glauco.

Veamos ahora cómo está introducida la cita en el discurso. El nombre de

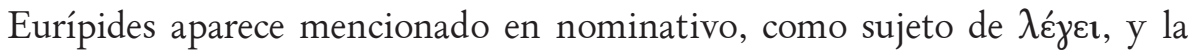

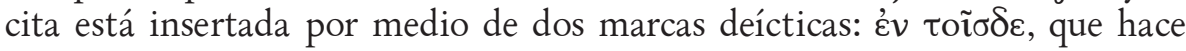
referencia a los versos que se van a introducir, es ya un nexo presentador, pero Platón refuerza la deixis intertextual mediante la adición del participio del verbo $\lambda \varepsilon ́ \gamma \omega$ en nominativo, dependiente de Eủpı $\pi \dot{\delta} \delta \eta s ;$ tenemos, por tanto,

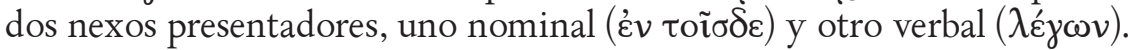

Atendiendo a la métrica y a la comparación con las otras fuentes transmisoras del fragmento, estaríamos ante una cita literal, que no habría sufrido ningún cambio para adaptarse a su nuevo contexto sintáctico. Hay que señalar, eso sí, que Platón no reproduce el segundo trímetro entero, tan sólo el primer metro y la mitad del segundo, sin que se altere el sentido fundamental de la frase: con

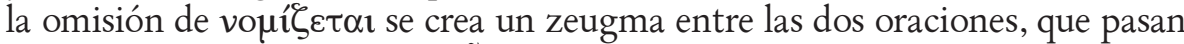
a depender del mismo verbo, zĩvol, con lo que se establece una mayor relación

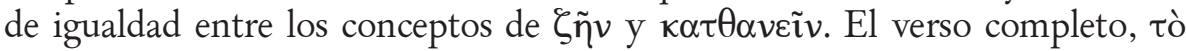

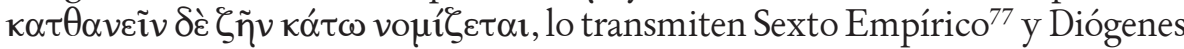

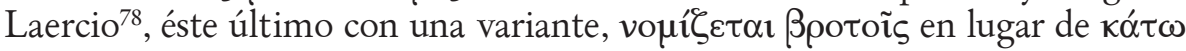

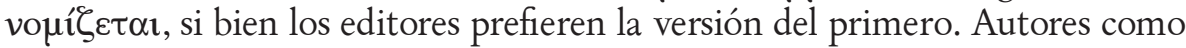
Clemente de Alejandría ${ }^{79}$ u Orígenes $^{80}$, citan el segundo verso como Platón, omitiendo las dos últimas palabras. Era habitual que este tipo de fragmentos, tan frecuentemente utilizados en la tradición indirecta y en las compilaciones gnomológicas, sufrieran recortes o añadidos en función de la finalidad con la que son citados o de los gustos de la persona que los empleóo ${ }^{81}$.

Se trata, como podemos observar, de una cita muy usada en la Antigüedad, famosa desde muy pronto a juzgar por la parodia que le dedica Aristófanes en Ranas $1477^{82}$, y cuya celebridad ha llegado hasta nuestros días, como

${ }^{75}$ Cf. Jouan-Van Looy, Fragments, $2^{e}$ partie, $555-7$.

${ }^{76} \mathrm{La}$ disputa se habría desatado a raíz de que Poliido se declarase incapaz de devolver a la vida a Glauco.

${ }_{77}^{7}$ S.E. P. 2.229 .

${ }_{78}^{78}$ D.L. 9.73.

${ }^{79}$ Clem. Al. Strom. 3.15.3.

${ }^{80}$ Origenes, Cels. 7.50

${ }^{81}$ Cf. C. Pernigotti, "Euripide nella tradizione gnomologica antica", en L. Battezzato, Tradizione testuale e ricezione letteraria antica della tragedia greca, Atti del convegno Scuola Normale Superiore, Pisa 14-15 Giugno 2002, Amsterdam 2003, 97-112; aquí, 107-9.

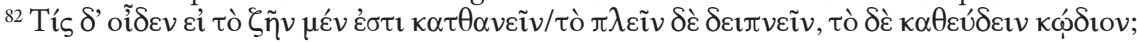
“¿Quién sabe si vivir es morir, respirar comer, y dormir un vellón?". 
demuestra el hecho de que una película de 1948, Portrait of Jennie ${ }^{83}$, comience con una traducción de los versos al inglés, mencionando la autoría de Eurípides.

A diferencia de lo que ocurría con la Antíope, en este caso la cita no tiene por qué sustentarse necesariamente en la lectura del drama o en la asistencia a su representación teatral, sino que, al tratarse de un verso célebre ya por entonces, Platón podría haberlo conocido también de manera indirecta. Esto no quiere decir, sin embargo, que el filósofo no hubiese podido ver el Poliido en escena: por la parodia de Aristófanes ${ }^{84}$ y las posteriores alusiones de Menandro ${ }^{85}$, podemos deducir que el drama estaría vigente en el panorama teatral al menos hasta principios de época helenística, no figurando ya entre los temas euripideos evocados por el teatro latino.

Es el momento de concluir. Hemos podido ver en el Gorgias dos usos distintos del texto de Eurípides. Uno, el de las citas de la Antíope, que implica una familiaridad con la obra que sólo otorga la asistencia a su representación en el teatro o la lectura; el interés de Platón por este drama trasciende lo meramente filosófico y pone de manifiesto su faceta de literato, no limitándose a reproducir el texto, sino reelaborándolo para adaptarlo a sus intereses. El otro, el del Poliido, que no sugiere ninguna familiaridad con la obra, sino que responde a un interés puntual por ilustrar una idea muy antigua sobre la vida y la muerte, para la que los versos de Eurípides constituyen un buen punto de partida. Es posible que esta cita, aunque no pueda considerarse propiamente

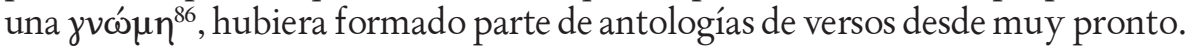
Por otro lado, a pesar de las diferencias a las que acabamos de aludir, todas las citas tienen una función de peso en el desarrollo argumentativo del discurso.

En el caso de la Antíope, no creemos que se pueda hablar sin más de imprecisiones memorísticas: es totalmente posible que la memoria de Platón albergase los pasajes de forma más literal, pero prefiriese adaptarlos a la informalidad de su prosa; de ahí que tienda a parafrasear buena parte de los versos y a dejar otros citados literalmente en la parte final, quizá como recurso ornamental. Además, sus paráfrasis se acercan bastante al modelo original, manteniendo la mayor parte de las palabras, y cambiando algunas

${ }^{83}$ Se realizó en EE.UU bajo la dirección de William Dieterle, inspirada en la novela de Robert Nathan con el mismo título, publicada en 1940.

${ }^{84}$ Aristófanes habría escrito también un Poliido, posiblemente parodiando el de Eurípides.

${ }^{85}$ Cf. Pertusi, "Selezione teatrale", 125-6, sobre las alusiones a las tragedias de Eurípides en la Comedia Nueva.

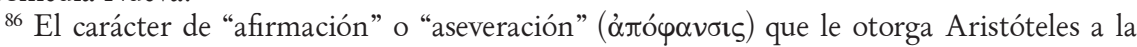
¡vó $\mu \eta$ en Retórica 2.21, es el primer factor que nos impide considerar estos versos como tal, por su forma interrogativa y su carácter dubitativo. Sobre las juć $\mu \alpha \mathbf{r}$ en Eurípides, cf. G. W.

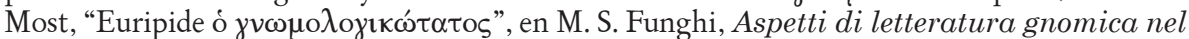
mondo antico, Firenze 2003, I, 141-66. 
por otras que encajarían mejor en su nuevo contexto (fr. 185, $\mu \varepsilon \imath \rho \alpha \kappa ı \omega ́ \delta \varepsilon \imath$

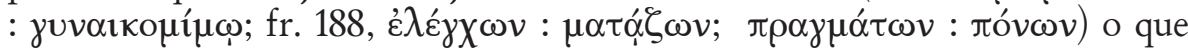
permitiesen a Calicles ridiculizar las actividades de Sócrates, al haber sido

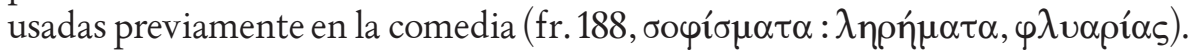
A la misma necesidad de adaptación se debe la supresión de las palabras o

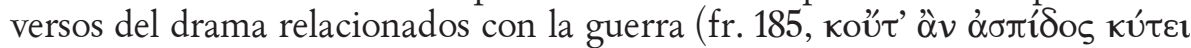

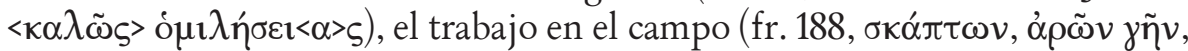

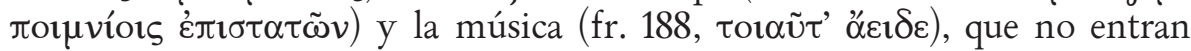
dentro de los intereses de los interlocutores del Gorgias. 